\title{
EFEKTIFITAS PENDEKATAN SAINTIFIK DALAM PEMBELAJARAN IPA UNTUK MENINGKATKAN HASIL BELAJAR SISWA TUNAGRAHITA DI HOME SCHOOLING PRIMAGAMA MALANG
}

\author{
Nuril Nuzulia \\ Universitas Islam Negeri Maulana Malik Ibrahim Malang, Indonesia \\ nurilnuzulia@gmail.com
}

\begin{abstract}
The scientific approach is a learning process designed to enable students to learn actively by doing the $5 \mathrm{M}$ process of observing, asking, trying, reasoning and communicating. Learning by using a scientific approach can encourage students to find out from various sources by making observations and not just receiving knowledge from teachers. The purpose of this research is to know the effectiveness of the scientific approach in improving the learning outcomes of the 4 th grade students in natural science learning materials of various forms of leaf bone, stems, and roots in Home Schooling Primagama Malang and SLB Tarik Sidoarjo. This research uses a quantitative approach with a simple experimental research type. Method in the form of observation, interviews, questionnaires and documentation. From the 4th grade of Home Schooling Primagama Malang and SLB Tarik Sidoarjo, 2 classes were taken: the experimental class (Home Schooling Primagama Malang) and the control class (SLB Tarik Sidoarjo) with 5 students Home Schooling Primagama Malang and 7 students of SLB Tarik Sidoarjo. Analysis used Independent $t$ test with SPSS 16 tool. From the research result can know the average value of learning result of experiment class 91 , mean while control class average learning result 78 and Sig 0,001<0,05 then Ho rejected, its mean that there is a difference in learning outcomes from the experimental class with the control class. So it can be concluded that the very effective approach can improve the learning of natural science with the material of various forms of leaf bone, stems, and roots in Home Schooling Primagama Malang.
\end{abstract}

Keyword: Scientific approach; learning outcomes; Natural Science

Copyright (c) 2017 Madrasah Jurnal Pendidikan dan Pembelajaran Dasar. All Right Reserved

\section{A. PENDAHULUAN}

Pendekatan pembelajaran merupakan titik tolak atau sudut pandang pendidik terhadap proses pembelajaran, yang dapat merujuk pada pandangan tentang terjadi proses yang sifatnya umum, yang mewadahi, menginspirasi, menguatkan, dan melatari metode pembelajaran dengan cakupan teoritis tertentu.

Menurut Muhammad Fadhillah (2013:12) dalam dunia pendidikan pendidik diharuskan menggunakan pendekatan yang sesuai dengan karakter peserta didik. Penggunaan pendekatan yang sesuai kepada peserta didik dapat menentukan sikap dan perbuatan. Pendidik yang memandang peserta didik sebagai pribadi yang berbeda satu dengan yang lainnya, akan berbeda dengan pendidik yang memandang peserta didik sama. Maka sangatlah perlu meluruskan pandangan yang keliru dalam menilai peserta didik. Pendidik perlu menyadari bahwasannya peserta didik merupakan individu dengan

Vol. 10 No. 1, Desember 2017

Madrasah homepage: http://ejournal.uin-malang.ac.id/index.php/madrasah/index 
segala perbedaan, sehingga sangatlah diperlukan suatu pendekatan dalam proses belajar mengajar (Dimyati, 2006:32).

Pendekatan saintifik (Trianto, 2001: 22) diatur dalam Permendikbud No 65 tahun 2013 tentang Standar Proses Pendidikan Dasar dan Menengah. Pembelajaran saintifik merupakan pembelajaran yang mengadopsi langkah-langkah saintis dalam membangun pengetahuan melalui metode ilmiah. Dalam pembelajarannya, pendekatan saintifik menyentuh tiga ranah yaitu pengetahuan, keterampilan, dan sikap. Aplikatif dari pendekatan saintifik adalah mengamati, menanya, manalar, mencoba, menyimpulkan dan mengkomunikasikan.

Menurut Nana Sujdana (2009:25) keberhasilan siswa dalam proses pembelajaran dipengaruhi oleh faktor individu sendiri dan factor dari luar individu. Faktor dari dalam siswa contohnya hasil belajar siswa. Hasil belajar adalah kemampuan-kemampuan yang dimiliki siswa setelah menerima pengalaman belajar. Hasil belajar siswa di pengaruhi oleh kemampuan siswa dan kualitas pengajaran. Kualitas pengajaran yang dimaksud adalah guru. Kemampuan dasar guru baik di bidang kognitif, bidang sikap, dan perilaku.

Berdasarkan hasil observasi yang dilakukan peneliti di Home Schooling Primagama Malang pada tanggal 25 Juli 2017 dan SLB Tarik Sidoarjo pada tanggal 5 Agustus 2017 terdapat hasil belajar yang rendah di kelas IV pada pembelajaran IPA materi macammacam bentuk tulang daun, batang, dan akar. Hal ini dikarenakan pemahaman materi yang sangat kurang, motivasi belajar menurun, guru belum menggunakan pendekatan yang dapat membuat pembelajaran lebih bermakna sehingga pembelajaran dirasa sangatlah monoton. Meskipun di Home Schooling belum seutuhnya menggunakan kurikulum 2013, namun guru belum juga menerapkan pembelajaran dengan menggunakan pendekatan saintifik. (Prabowo,2010: 15) Pendekatan saintifik adalah pendekatan yang dapat dilakukan baik dalam kurikulum KTSP maupun kurikulum 2013.

Hal ini dapat dilihat saat guru mengajarkan materi macam-macam bentuk tulang daun, batang, dan akar, guru hanya menggunakan metode ceramah dan menunjukkan gambar macam-macam bentuk tulang daun, batang, akar tanpa harus peserta didik mengamati di lingkungan sekitar dan mencoba mencari macam-macam daun, batang, dan akar yang memiliki bentuk tulang daun, karakteristik batang, dan akar yang berbeda. Guru juga sering memberikan soal-soal kepada peserta didik, tanpa adanya pembahasan yang kompleks seperti perwakilan siswa di suruh maju ke depan kelas memaparkan jawabannya. Pembelajaran yang seperti ini membuat peserta didik merasa bosan, dan pemahaman mereka mengenai materi tersebut belum di dapat seutuhnya.

Menyadari bahwa Anak Berkebutuhan Khusus adalah individu yang unik. Keunikan ini mengandung pengertian bahwa ABK mempunyai sifat-sifat khusus atau karakteristik yang berbeda antara yang satu dengan yang lainnya, baik dalam segi kemampuan, bakat, minat maupun gaya belajarnya. Mendidik siswa di sekolah luar biasa tidak sama dengan mendidik siswa di sekolah umum. Yang perlu dipahami oleh pendidik yang memiliki siswa tunagrahita antara adalah guru harus memahami karakter anak tunagrahita yang memiliki keunikan tersendiri yaitu bersifat pelupa, susah memahami perintah yang kompleks, perhatian mudah terganggu, dan susah memahami hal-hal yang kompleks. Oleh karena itu guru siswa tunagrahita harus sabar, penyayang, mengajar dengan kata-kata sederhana dan gambar yang nyata.

Menurut Nunung (2010:3) pembelajaran pada anak tunagrahita hendaknya dilakukan dengan pola pembelajaran yang menyenangkan. Dalam pengertiannya harus membuat motivasi belajar dan mengedepankan proses sehingga anak menjadi aktif, menyenangkan, dan jauh dari kata bosan di dalam kelas. Dalam pembelajaran guru

Vol. 10 No. 1, Desember 2017

Madrasah homepage: http://ejournal.uin-malang.ac.id/index.php/madrasah/index 


\section{MADRASAH}

Jurnal Pendidikan dan Pembelajaran Dasar

p ISSN: 1979-5599 | e ISSN: 2502-194X

P a g e | 3

hendaknya menggunakan bahasa yang mudah dipahami, menggunakan contoh-contoh yang sederhana, serta dilakukan dengan menarik dan menyenangkan dengan diberikan beberapa metode dan pendekatan sehingga anak tunagrahita tidak cepat bosan dan mendapatkan peningkatan hasil belajar.

Ilmu pengetahuan Alam adalah ilmu yang mempelajari alam sekitar dan merupakan salah satu mata pelajaran yang diterima oleh peserta didik tunagrahita. Di dalam mata pelajaran IPA terdapat tiga kemampuan yaitu: (1) kemampuan untuk mengetahui apa yang di amati, (2) kemampuan untuk memprediksi apa yang belum diamati, dan kemampuan untuk menguji tindak lanjut hasil eksperimen, (3) dikembangkannya sikap ilmiah. Hal ini akan tepat jika memang disandingkan dengan pendekatan saintifik. Namun dalam perbedaan kemampuan peserta didik umum dengan anak tunagrahita, maka pembelajaran dengan menggunakan pendekatan saintifik pada mata pelajaran IPA bagi anak tunagrahita membutuhkan modifikasi yang sesuai dengan karakteristik tunagrahita.

Dalam penelitian terdahulu menyebutkan bahwa pendekatan saintifik dapat memberikan pengaruh yang signifikan dalam meningkatkan motivasi belajar. Seperti yang di ungkapkan Wahyu Agus Styani dalam jurnalnya yang berjudul Pelaksanaan Pendekatan Saintifik Berbasis Ice Breaker Pada Pembelajaran IPA Bagi Anak Tunagrahita Ringan di SLB C YPAC Semarang bahwa pendekatan saintifik dapat meningkatkan motivasi belajar dan hasil belajar siswa meningkat. Dan proses pembelajaran akan dapat berjalan dengan sangat menyenangkan sehingga dapat menumbuhkan dan meningkatkan motivasi belajar siswa dalam memahami materi IPA.

\section{B. METODE PENELITIAN}

Penelitian dilaksanakan di Home Schooling Primagama Malang pada semester ganjil tahun 2017/2018. Sampel dari seluruh subjek penelitian adalah 2 kelas yakni kelas di Home Schooling Primagama Malang dan SLB Tarik Sidoarjo. Variabel bebas penelitian adalah pembelajaran Ilmu Pengetahuan Alam dengan pendekatan saintifik, sedangkan untuk variabel terikat penelitian adalah hasil belajar.

Jenis penelitian adalah penelitian eksperimen dengan teknik pengumpulan data yaitu observasi awal, wawancara tidak terstruktur, metode tes, dan dokumentasi. Tahap penelitian adalah persiapan penelitian dengan melaksanakan observasi awal untuk identifikasi masalah dan analisis akar penyebab masalah, selanjutnya menentukan subjek dan sampel, dilanjutkan dengan menyusun instrumen penelitian. Instrument yang digunakan berupa buku pembelajaran Ilmu Pengetahuan Alam kelas 4 dan lembar tes tulis.

Tahap selanjutnya adalah pelaksanaan penelitian dengan menggunakan 2 sampel kelas 4, untuk kelas eksperimen menggunakan pembelajaran saintifik yakni kelas 4 di Home Schooling Primagama Malang, sedangkan untuk kelas kontrol tidak menggunakan pendekatan saintifik yakni kelas 4 di SLB Tarik Sidoarjo. Selama 2 minggu pertemuan dikelas guru menggunakan pendekatan saintifik dalam pembelajaran Ilmu Pengetahuan Alam. Tahap terakhir yaitu pengolahan data, pembahasan, dan pengambilan kesimpulan.

\section{HASIL DAN PEMBAHASAN}

1. Hasil
a. Hasil uji pre test dan post test

Vol. 10 No. 1, Desember 2017

Madrasah homepage: http://ejournal.uin-malang.ac.id/index.php/madrasah/index 
Tabel nilai pre-test dan post-test yang didapat dari peserta didik kelas 4 Home Schooling Primagama Malang pada saat uji coba lapangan adalah sebagai berikut:

Tabel C.1 Hasil Uji Coba Lapangan pada Pre-Test

\begin{tabular}{l|l|l|l}
\hline Kriteria & $\mathrm{N}$ & $\mathrm{P}(\%)$ & Keterangan \\
\hline$<70$ & 3 & $60 \%$ & Tidak tuntas \\
\hline$>70$ & 2 & $40 \%$ & Tuntas \\
\hline
\end{tabular}

Pada tabel 1.1 hasil pre test menunjukkan bahwa peserta didik yang kurang dari KKM adalah sebanyak 3 siswa, dan peserta didik yang mencapai KKM sebanyak 2 siswa, maka pembelajaran Ilmu Pengathuan Alam di kelas 4 dikatakan masih belum tuntas.

Tabel C.2 Hasil Uji Coba Lapangan pada Post-Test

\begin{tabular}{llll}
\hline Kriteria & $\mathrm{N}$ & $\mathrm{P}(\%)$ & Keterangan \\
\hline$<70$ & 0 & - & - \\
\hline$>70$ & 5 & $100 \%$ & Tuntas \\
\hline
\end{tabular}

Pada tabel 1.2 hasil post test menunjukkan bahwa peserta didik yang kurang dari KKM tidak ada, dan peserta didik yang mencapai KKM sebanyak 5 dengan mencapai prosentase $100 \%$, maka pembelajaran Ilmu Pengetahuan Alam dengan materi macammacam tulang daun, batang, dan akar di kelas 4 dikatakan tuntas.

Hal ini menunjukkan keefektifan dari pemberian pendekatan saintifik. Di lihat dari hasil post test pada table 1.2 dapat membuktikan pentingnya pembelajaran dengan menggunakan pendekatan saintifik pada pembelajaran Ilmu Pengetahuan Alam lebih efektif dan penting untuk di terapkan bagi peserta didik tunagrahita di sekolah dasar.

\section{b. Independent Samples Test}

Data nilai pre test dan post test tersebut selanjutnya melalui independent samples test dengan bantuan computer SPSS 16. Hasil analisis uji t independent samples test adalah sebagai berikut:

\section{Group Statistics}

\begin{tabular}{cccccc}
\hline & eksperimen_kontrol & N & Mean & Std. Deviation & Std. Error Mean \\
\hline \multirow{2}{*}{ nilai } & 1 & 5 & 91.40 & 2.191 & .980 \\
\cline { 2 - 6 } & 2 & 6 & 78.00 & 5.099 & 2.082 \\
\hline
\end{tabular}

Vol. 10 No. 1, Desember 2017

Madrasah homepage: http://ejournal.uin-malang.ac.id/index.php/madrasah/index 


\section{MADRASAH}

Jurnal Pendidikan dan Pembelajaran Dasar

p ISSN: 1979-5599 | e ISSN: 2502-194X

Page $\mid 5$

\section{Independent Samples Test}

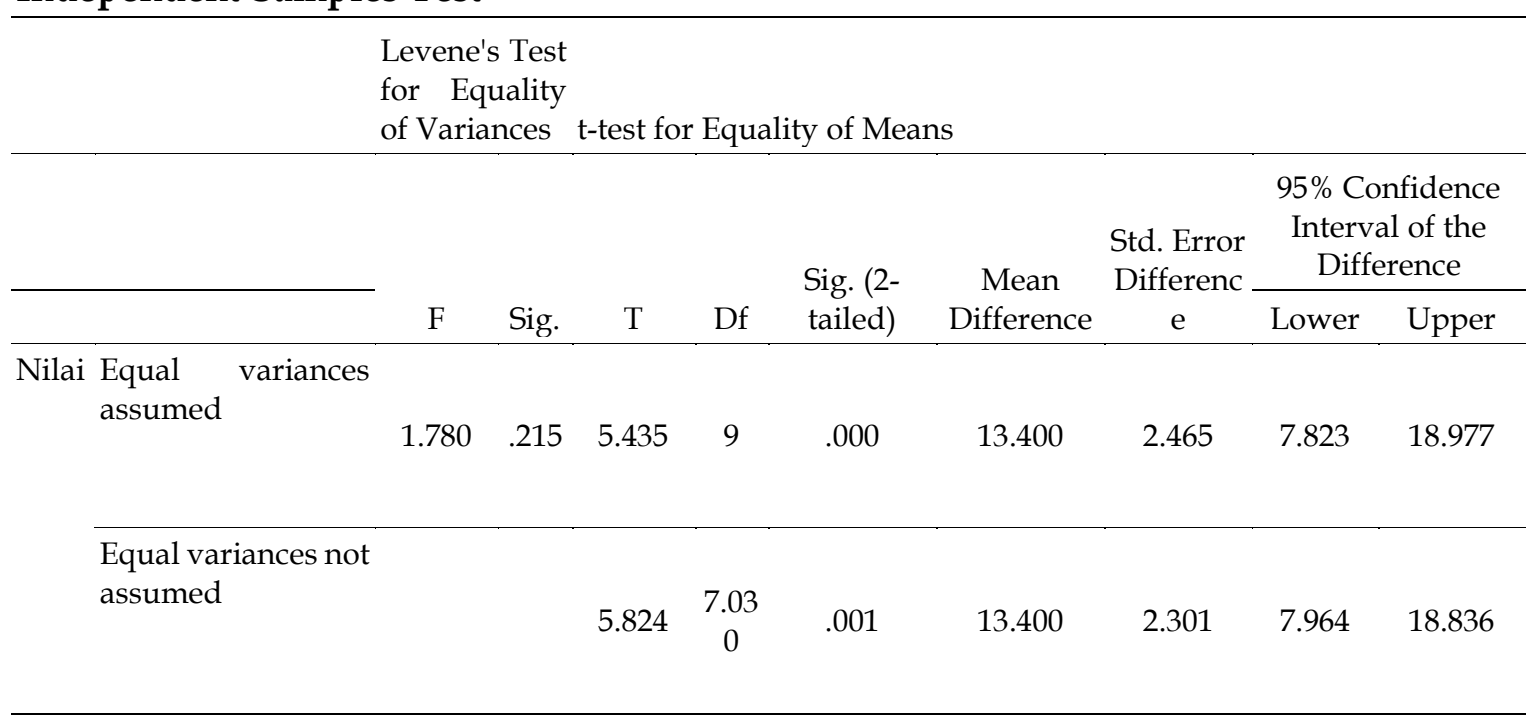

Dalam mengambil keputusan, dapat dilihat dari sig (2 tailed), apabila sig < 0,05 maka Ho ditolak dan Ha diterima.

Hal ini dapat dilihat bahwa hasil belajar sesudah menggunakan pendekatan saintifik lebih efektif dari pada sebelumnya. Data sig 0,001 yang diperoleh dari hasil uji ttes yang menunjukkan bahwa ada perbedaan yang signifikan antara hasil belajar peserta didik sesudah menggunakan pendekatan saintifik dibandingkan dengan sebelum menggunakan pendekatan saintifik.

Dalam mengambil keputusan dengan penghitungan manual, maka dari data yang telah diperoleh dapat diidentifikasi bahwa skala datanya adalah interval karena ada tingkatan, distrbusi populasinya normal, pengolahan datanya menggunakan Dependent sample t-test. Kriteria ujinya adalah uji-t pada dependent sample test.

Adapun rumusan Ha nya adalah ada perbedaan yang signifikan pada hasil belajar peserta didik kelas 4 di Home Schooling Primagama Malang setelah menggunakan pendekatan saintifik.

Hipotesisnya adalah diterima karena $t$ hitung $>$ dari $t$ tabel, sehingga kesimpulannya, ada perbedaan yang signifikan pada hasil belajar peserta didik kelas 4 Home Schooling Primagama Malang setelah menggunakan pendekatan pada pembelajaran Ilmu Pengetahuan Alam dan dapat dikatakan bahwa pendekatan saintifik secara signifikan efektif untuk meningkatkan hasil belajar peserta didik.

\section{c. Hasil Belajar ranah kognitif}

Hasil belajar pada ranah kognitif sebagai berikut:

Table C.3 hasil belajar ranah kognitif

\begin{tabular}{llcc}
\hline No & Uraian & \multicolumn{3}{c}{ Nilai kognitif } & \\
\hline & & $\begin{array}{l}\text { Pembelajaran IPA di Home } \\
\text { Schooling Primagama Malang }\end{array}$ & $\begin{array}{l}\text { Pembelajaran IPA di SLB } \\
\text { Tarik Sidoarjo }\end{array}$ \\
\hline 1. & Jumlah siswa & 5 & 7 \\
\hline 2. & Nilai minimum kognitif & 90 & 70 \\
\hline
\end{tabular}

Vol. 10 No. 1, Desember 2017

Madrasah homepage: http://ejournal.uin-malang.ac.id/index.php/madrasah/index 


\begin{tabular}{llll}
\hline 3. & Nilai maximum kognitif & 95 & 85 \\
\hline 4. & Rata-rata nilai kognitif & 91 & 78 \\
\hline
\end{tabular}

Untuk lebih jelasnya dapat dilihat pada gambar C.1. Grafik perbadingan hasil belajar ranah kognitif sebagai berikut:

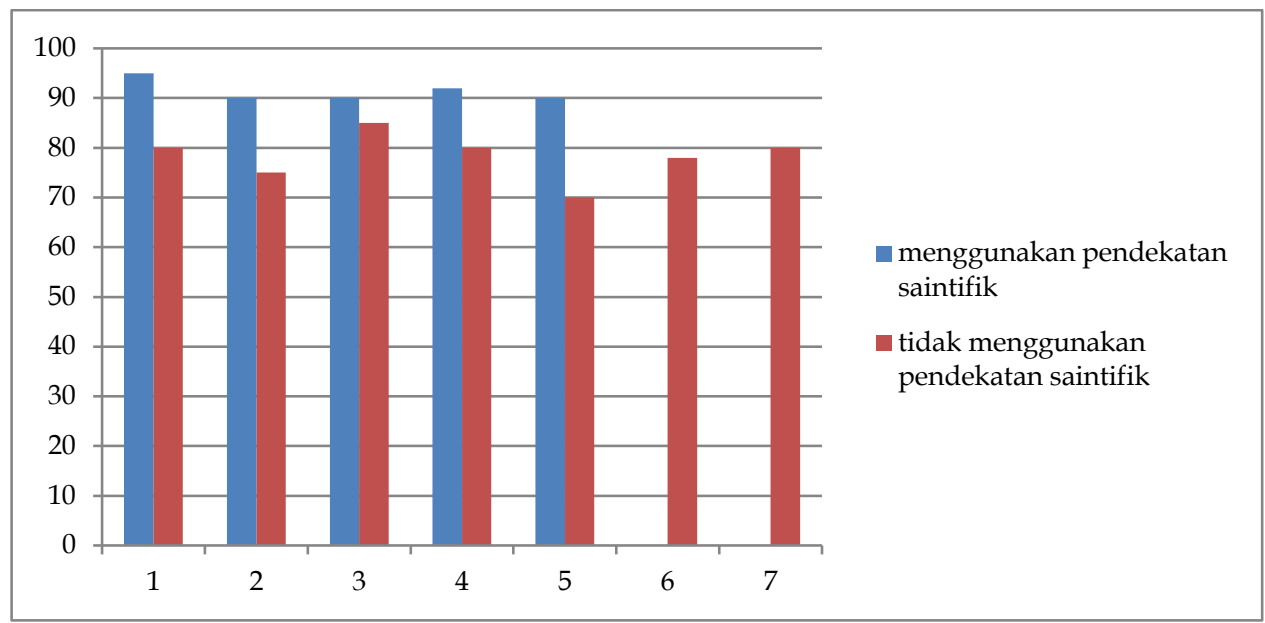

Gambar 1. Grafik hasil belajar ranah kognitif

\section{Pembahasan}

Proses pembelajaran adalah proses dari serangkaian pelaksanaan oleh guru dan peserta didik yang berlangsung dalam suasana pembelajaran edukatif untuk mencapai tujuan pembelajaran. Syarat utama dalam proses pembelajaran adalah dengan adanya hubungan timbal balik antara guru dan peserta didik. Agar tercipta suatu proses pembelajaran yang efektif, guru dituntut agar mampu mengelola proses pembelajaran yang memberikan rangsangan kepada peserta didik sehingga ia mampu dan mampu belajar.

Guru memiliki peran yang sangat penting dalam menentukan kualitas pebelajaran di kelas maupun di luar kelas. Oleh karena itu, guru hendaknya selalu memikirkan tentang bagaimana upaya yang dilakukan dalam meningkatkan proses pembelajaran, diantaranya dengan menggunakan sebuah pendekatan yang sesuai dengan karakter peserta didiknya.

Dalam mempelajari pembelajaran Ilmu Pengetahuan Alam materi macam-macam tulang daun, batang, dan akar yang di bungkus dengan pendekatan saintifik peserta didik banyak melakukan kegiatan menanya, manalar, mencoba,mengamati, menyimpulkan dan mengkomunikasikan yang dapat membuat peserta didik lebih faham tentang manfaat materi yang dipelajari untuk kehidupannya.

Uji independent samples test menunjukkan Sign 0,001 < 0,05 maka Ho ditolak sehingga ada perbedaan yang signifikan pada pemberian pendekatan saintifik pada pembelajaran Ilmu Pengetahuan Alam di Home Schooling Primagama Malang. Perbedaan ini dapat dilihat dari rata-rata hasil belajar kelas eksperimen (kelas yang menggunakan pendekatan saintifik) rata-rata adalah 91, sedangkan hasil rata-rata hasil belajar peserta didik kelas control (kelas yang tidak menggunakan pendekatan saintifik) adalah 78.

Pendekatan saintifik adalah proses pembelajaran yang di bentuk sedemikian rupa agar peserta didik melakukan kegiatan seperti seorang sains di bidang ahlinya. Pendekatan saintifik dimaksudkan untuk memberikan pemahaman kepada peserta didik dalam mengenal, memahami beragam materi menggunakan pendekatan ilmiah. oleh karena itu

Vol. 10 No. 1, Desember 2017

Madrasah homepage: http://ejournal.uin-malang.ac.id/index.php/madrasah/index 


\section{MADRASAH}

Jurnal Pendidikan dan Pembelajaran Dasar

p ISSN: 1979-5599 | e ISSN: 2502-194X

P a g e $\mid 7$

kondisi pembelajaran diharapkan tercipta diarahkan untuk mendorong peserta didik dalam mencari tahu dari kegiatan obeservasi dan bukan hanya diberi tahu saja oleh guru. Pembelajaran dengan menggunakan pendekatan saintifik lebih disukai peserta didik karena membantu peserta didik menguasai tujuan pembelajaran dan mendapatkan hasil di atas KKM.

Hal ini didasarkan juga dengan penelitian terdahulu yang dilakukan oleh Novia Diah Ekawati (Jurnal UNESA: 2), dengan menggunakan pendekatan saintifik kompetensi energi panas siswa tunarungu dapat meningkat melalui pengamatan, pengukuran, menjelaskan, dan menyimpulkan secara ilmiah tentang materi yang disampaikan, selain itu melalui pendekatan saintifik dapat merangsang siswa dalam mengemukakan ide, gagasan, dan berfikir tingkat tinggi dalam memecahkan sebuah masalah secara ilmiah.

Penelitian yang dilakukan Tyas Rahmawarni (nd:3) menyatakan bahwa penerapan pendekatan saintifik merupakan salah satu pendekatan pembelajaran yang dapat menciptakan pembelajaran yang aktif dan bermakna, sehingga jika diterapkan pada peserta didik tunarungu dapat membantu peserta didik dalam menerima informasi dan mengingat materi. Pengetahuan peserta didik tunarungu tentang pertumbuhan pada tanaman disini merupakan kemampuan peserta didik dalam mengingat dan mengungkapkan kembali segala informasi yang telah dipelajari.

Pembelajaran dengan menggunakan pendekatan saintifik sangatlah diminati oleh peserta didik bahkan meningkatkan antusias dalam belajar. Beberapa kelemahan pembelajaran Ilmu Pengetahuan Alam dikarenakan tidak menggunakan pendekatan saintifik dan peserta didik sangat bosan dengan pembelajaran yang ada.

\section{SIMPULAN}

Nilai Sig. 0,001 < 0,05 maka Ho ditolak sehingga dapat disimpulkan bahwa menggunakan pendekatan saintifik dalam pembelajaran sangatlah efektif dalam meningkatkan hasil belajar peserta didik di Home Schooling Primagama Malang. Perbedaaan kelas yang menggunakan pendekatan saintifk (kelas eksperimen 4 Home Schooling Primagama Malang) dan kelas tidak menggunakan pendekatan saintifik (kelas control 4 SLN Tarik Sidoarjo) dapat dilihat dengan rata-rata hasil belajar yang diperoleh, yaitu kelas eksperimen dengan rata-rata 91 sedangkan kelas control dengan nilai rata-rata 78. Pembelajaran dengan menggunakan pendekatan saintifik pada pembelajaran Ilmu Pengetahuan Alam lebih dimininati peserta didik karena lebih dapat memahami materi, mereka dapat menggali pengetahuan sendiri, dan pembelajaran berlandaskan kerja ilmiah.

\section{REFERENSI}

Agus, Wahyu. Pelaksanaan Pendekatan Saintifik Berbasis Ice Breaker Pada Pembelajaran.

Apriyanto, Nunung. (2010). Seluk Beluk Tunagrahita dan Strategi Pembelajarannya, Yogyakarta: Javalitera.

Daryanto. (2014). Pendekatan Pembelajaran Saintifik Kurikulum 2013. Yogyakarta: Gava Media.

Dimyati dan Mudjiono. (2006) . Belajar dan Pembelajaran. Jakarta: PT Rineke Cipta.

Fadhillah, M. 2014. Implementasi Kurikullum 2013 Dalam Pembelajaran SD/MI, SMP/MTs, E SMA/MA. Yogyakarta: Ar-Ruzz Media3

Vol. 10 No. 1, Desember 2017

Madrasah homepage: http://ejournal.uin-malang.ac.id/index.php/madrasah/index 
Prabowo. (2010). Konsep Pembelajaran Terpadu: Konsep, Strategi, dan Implementasisinya dalam KTSP. Jakarta: Bumi Aksara.

Usman, M. Uzer. (2006). Menjadi Guru Profesional. Bandung: PT Remaja Rosda Karya.

Sudjana, Nana. (2009). Penilaian Hasil Proses Belajar Mengajar. Bandung: PT Remaja.

Rachmawani, Tyas. Penerapan Pendekatan Saintifik Untuk Meningkatkan Pengetahuan Peserta Didik Tunarungu Tentang Pertumbuhan Pada Tanaman Di Kelas D2 SLB Negeri Ciamis, (UPI: Jurnal)

Novia. (2016). Pendekatan Saintifik Terhadap Kompetensi Konsep Energi Panas Pada Anak Tunarungu. Universitas Negeri Surabaya: Jurnal

IPA Bagi Anak Tunagrahita Ringan di SLB C YPAC Semaran.Universitas Negeri Semarang: Jurnal

Sandjaja, Albetrus dan Heriyanto. (2011). Panduan Penelitian. Jakarta: Prestasi Pustakarya.

Trianto. (2001). Mengembangkan Model Pembelajaran Tematik. Jakarta: Prestasi Pustaka. 